УДК 8:80:801

\author{
ГЛАГОЛЫ РЕЧИ КАК МАРКЕРЫ ПСИХОЛОГИЧЕСКОГО ТИПА \\ ЛИЧНОСТИ (НА МАТЕРИАЛЕ ПОВЕСТИ В. П. АКСЕНОВА \\ «ЗВЕЗДНЫЙ БИЛЕТ»)
}

(C) Лилия Бормусова

\title{
VERBS OF SPEECH AS MARKERS OF PSYCHOLOGICAL PERSONALITY TYPE (BASED ON THE NOVEL "A TICKET TO THE STARS" BY V. P. AKSENOV)
}

\section{Lilya Bormusova}

The analysis of text at the intersection of various scientific trends is the research focus of different areas in modern philology, such as linguistics, text theory, theory of communication, psychology and literary studies. In this case, literary text acts as one of the ways of implementing the language system, which allows us to identify the character by his/her speech behavior.

The object of the study is the verbs of speech behavior. By analyzing them, we can identify and describe in detail psychological characteristics of one of the main characters in V. P. Aksenov's story "A Ticket to the Stars", Dimka - a school leaver, who is at a turning point in his life. The purpose of the work is to study the speech behavior of an extroverted personality type taking into account his linguistic and psychological characteristics. The author describes his protagonist's various experiences and the formation of his personality, which allows the reader to better know and understand the features of his character. The author focuses his attention on the verbs of speech, revealing the patterns of their use, which illustrate the speech behavior of the extrovert. As a result, the conclusions are made about the scientific novelty of the study. Based on the analysis of the linguistic material of the story and the theses of leading psychologists, the article concludes that the verbs of speech act here as markers of a psychological personality type.

Keywords: psychological type of personality, literary text, verbs of speech, extroverted personality type, Aksenov V. P.

Одним из актуальных направлений современной филологии является анализ текста на стыке различных научных направлений, таких как лингвистика, теория текста, теория коммуникации, психологии и литературоведения. При этом художественный текст выступает в качестве одного из основных способов реализации языковой системы, позволяющий идентифицировать персонажа по его речевому поведению.

Объектом исследования являются глаголы речевого поведения, анализ которых позволяет выявить и детально описать психологические особенности характера одного из основных героев повести В. П. Аксенова «Звездный билет» Димки - выпускника школы, переживающего переломный момент своей жизни. Цель работы - изучить речевое поведение экстравертного типа личности с учетом лингвистических и психологических характеристик. Автор, обращаясь к описанию различных переживаний героя, к его становлению как личности, дает возможность читателю лучше узнать и понять особенности характера своего героя. Основное внимание при этом автор акцентирует на глаголах речи, выявляя при этом определенные закономерности их употребления, иллюстрирующие речевое поведение экстраверта. В результате проведенного исследования сделаны определенные выводы, свидетельствующие о научной новизне предпринятого исследования. На основании анализа языкового материала повести, а также привлечения тезисов ведущих психологов автор устанавливает, что в повести глаголы речи выступают как один из маркеров психологического типа личности.

Ключевые слова: психологический тип личности, художественный текст, глаголы речи, экстравертный тип личности, Аксенов В. П. 
Одной из актуальных задач современной лингвистики является изучение речевой деятельности в художественном дискурсе для установления языковой объективации психологического типа личности. Как правило, в фокусе внимания исследователей оказывается языковая личность самого автора. Так, например, в статье М. В. Ляпон на основе синтеза речевых и психологических характеристик описывается психологический тип личности М. Цветаевой, относимый автором к интравертам [Ляпон]. Особый аспект анализа был предложен В. П. Беляниным, который художественные тексты подразделил на «весёлые», «светлые», «тёмные», «красивые» и т. п., при этом автор делает акцент на эмоциональнопсихологическое содержание текстов [Белянин].

За последнее десятилетие опубликовано определенное количество работ и выполнен ряд диссертационных исследований, так или иначе связанных с изучением творчества В. П. Аксёнова как с точки зрения литературоведения, так и лингвистики. Роман «Звёздный билет», написанный в 1961 г., также привлекал внимание филологов, однако он рассматривался, как правило, в общем ряду других произведений писателя и не был объектом специального изучения, хотя, как нам представляется, он является определённой вехой в творчестве писателя и заслуживает более пристального внимания, особенно с точки зрения его языковой организации. Существует ряд статей, в которых рассмотрены лексика и синтаксис произведений В. П. Аксёнова, однако до сих пор нет работ, посвященных описанию глагольной лексики как средству идентификации персонажей повести «Звёздный билет».

Цель данной статьи - рассмотреть глаголы речи как языковой элемент обозначения речевой деятельности, поскольку они являются одним из наиболее распространенных средств, связанных с передачей информации. Выделяя глаголы речи, мы опирались на понятие речевой деятельности, сформулированное в работах Л. С. Выготского, Л. Д. Кацнельсона, А. Н. Леонтьева, а также на работы Л. Г. Бабенко, В. П. Бахтиной, Л. М. Васильева, Е. С. Кубряковой, Г. В. Степановой и др. В понимании термина «речевая деятельность» лежит характеристика речи «как целостного процесса или акта, который имеет свою стержневую мотивацию и сопровождает все остальные виды деятельности человека и в то же время без них - существовать не может» [Зимняя, с. 64]. Согласно взглядам отечественных психологов Л.С. Выготского [Выготский] и Л. Д. Кацнельсона [Кацнельсон], речевая деятельность выступает как часть психологической жизни человека, она тесно связана с такими видами деятельности, как познание, ощущение, коммуникация. Кроме того, речевая деятельность тесно связана с возрастными особенностями индивида.

Вслед за Л.Г. Бабенко в данной статье мы будем использовать термин «глаголы речевой деятельности», подразделяя их на пять основных групп: 1) глаголы характеризованной деятельности; 2) глаголы сообщения; 3) глаголы общения; 4) глаголы обращения; 5) глаголы речевого воздействия [Толковый словарь русских глаголов, с. 349-379] (далее - ТСРГ).

Статистический анализ глаголов речевой деятельности в повести «Звёздный билет» позволил нам выделить 297 употреблений исследуемых лексем, при этом наиболее частотными являются речевые лексемы со значением характеризованной речевой деятельности, имеющие типовую семантику: «произносить (произнести) что-л. как-л., каким-л. образом, обнаруживая характерные артикуляционные особенности говорения или выражая при этом какие-л. внутренние эмоциональные состояния» [ТСРГ, с. 349]. Базовыми глаголами данной группы выступают глаголы говорить (сказать), которые имеют значение «словесно выражать мысль, сообщать» [Ожегов, Шведова, с. 134]. Они часто встречаются в тексте повести «Звёздный билет», при этом их значение может уточняться обстоятельственными конкретизаторами (бодро, мрачно, тихо, резко, едко, насмешливо), переводящими их в разряд функционального эквивалента гипонимов (предупредить, приказать, пожаловаться и т. п.). Количество их употреблений варьируется при речевой характеристике героев повести, в частности в диалогической и монологической речи одного из основных героев повести, Димки, мы выделили 42 употребления:

Димка сказал: "Волнение среди аборигенов» [Аксенов, с. 308]; «Что-то я не знаю такой машиньл», -мрачно сказал Димка [Там же, c. 301] (здесь и далее разрядка наша - Л. Б.); «Коньяк, - сквозь зубы, резко так сказал он, - Налейте коньяку. Четыре по сто» [Там же, c. 328]; "Я тебе дам совет, - тихо сказал Димка, - как увидииь этих девочек, беги от них подальше. Сразу, как увидишь, так и беги. Понял меня?» [Там же, с. 353]; «Галка идёт, - мрач но говорит Димка и тайком показывает мне: «Заткнись!» [Там же, с. 265]; «Ииь тыл, как раскричался», - насмешливо говорит Димка. [Там же, с. 286]; «Ещуе один иаг к коммунизму», - бодро сказал я [Там же, с. 433]; «Ax да, - говорюя едко, -ведь тьл же у нас 
засекреченный товарищ» [Там же, с. 446]; Димка сказал что-то ме-е-дленно, а потом долго гов орил что-то быстрое-быстрое [Там же, с. 377].

В первой части повести Димка - «юноша с безумными идеями в голове», по словам его старшего брата Виктора. Димка - компанейский парень, умеющий дружить, он всегда принимает решения за всех, жизнь кажется весёлой, забавной, все горизонты перед ним открыты, ему хочется уехать из своего старого дома, символа мещанской, старой жизни. Димка постоянно переходит от спокойной манеры говорить к экспрессивной, он не может себя контролировать, находится на взводе, как правило, он не говорит, а кричит. Согласно типологии Юнга, Димка соответствует экстравертному типу личности: очень активный, импульсивный, направленный на общение с людьми, мыслит, исходя из собственных убеждений, а не смотрит на картину мира в целом [Юнг, с. 260]. Димка еще подросток, но уже в стадии перехода в юность, ему присущи пока ещё все характерные черты подростка. Его смех, насмешки - временное неумение совладать со своими эмоциями, это распространённая защитная подростковая реакция, снимающая эмоциональное напряжение в ответ на волнующий стимул [Кон, с. 138].

Языковая объективация образа персонажа происходит на грамматическом уровне, прежде всего с помощью глаголов - маркеров психологического состояния героя в определенной ситуации взаимодействия с другими персонажами или на уровне внутреннего монолога. Показательны в этом плане глаголы со значением звукового оформления речи, они наиболее частотны (58 употреблений): орать (3), заорать (5), проорать (2), гаркнуть (5), выпалить (3), кричать (6), крикнуть (10), буркнуть (6), промямлить (4), пробормотать (4), бубнить (5), шептать (1), которые выстраиваются в определенный синонимический ряд с уровнем интенсивности произнесения.

Прямая речь, вводимая глаголами крикнуть (кричать), закричать, сопровождается восклицательными предложениями, эмоциональнооценочными междометиями, экспрессивной лексикой. Димка, несмотря на весь внешний антураж сильного и смелого парня, чувствует себя беспомощным, а единственной защитной реакцией, как ему представляется, пока является крик: «Знаешь, - крикнул он, - лучше бы ты осталась дома!» [Аксенов, с. 306]; «Правильно! - крикнул Димка. - Любви нет и не было никогда» [Там же, с. 309]; «Идиотка!»-крикнул он первое, что пришло в голову [Там же, с. 319].
Димка еще не научился управлять своим эмоциональным состоянием, каждое «вербальное воздействие в свой адрес он интерпретирует согласно своим психологическим установкам, не оценивая всей ситуации целиком» [Кулагина, Колюцкий, с. 198]: «Представьте себе, знаем! крикнул он. - В школе проходили. Учили нас труду. Труд - это такой урок, на котором хочется всё ломать» [Аксенов, с. 310]; «Да разве только труд! - закричал я в ответ. - Трудились люди во все века, и, по-моему, неплохо...» [Там же, с. 433]; «Дура!»-закричал Димка и отвернулся [Там же, с. 365].

Наивысшую степень психологического состояния характеризует глагол заорать: «Эй, Долгов!» - зао рал он, но кто-то выбил у него из рук ружье, кто-то зажал рот ладонью, кто-то поташил в лес. [Там же, с. 380]; «Врешь!»-заор ал он и вскочил на ноги [Там же, с. 365].

Глаголы речи, их комбинации способны фиксировать специфику отношений между участниками речевого процесса, имплицитно передавать целый диапазон разнообразных эмоций, настроений, чувств, влияющих на речевое (коммуникативное) поведение героя. В ситуации общения с официальными лицами Димка, как правило, бубнит: У будки регулировщика Димка бубни т : "И паспорта нету и денег...» [Аксенов, c. 259]; демонстрируя нежелание общаться, он бурчит: «Напиши это в стихах», - буркнул Димка [Там же, с. 319]; «Идите, девочки, мы потом», -буркнул Димка [Там же, с. 348]; «Не помню», -буркнул Димка [Там же, с. 350]; «И подработать денег на дорогу», - буркнул Димка [Там же, с. 382].

Димка не знает, как себя вести с Галкой, он или мямлит, или бубнит, или впадает в другую крайность: «Ладно, Галя, я тебя жду», - промямлил он и поплёлся наверх к лесу [Там же, с. 336]; «Знаешь, Галка, любовь должна быть свободной!» - в ы п ал ил Димка [Там же, с. 339]; Он ударил её ладонью по плечу и бодро воскликнул: "Не трусь, детка! Держи хвост пистолетом!» [Там же, с. 306]; Димка резко повернул голову и отскочил. "T Ты что?! - гарк нул он. - Чего тебе надо?». "Дай мне сигарету, капитан, - сыграла Галя. «Ты уверена, что Брижит Бардо курит?» - буркнул Димка и протянул ей сигарету [Там же, с. 305]. И даже когда Галка кричит, он говорит спокойно, хотя и с восклицательной интонацией, он старается контролировать свои эмоции: «Орёл!»-кричит Галя. «Решка!» - говорит Димка [Там же, c. 266].

В отношениях со старшим братом Димка, пытаясь самоутвердиться, как правило, говорит 
ехидно, злобно, насмешливо, язвительно или кричит: «Не беспокойся, всё твоё любимое», язвительно отвечает Димка [Там же, c. 260]; Тогда Димка начинает ех и дн и ча ть . «Ученым можешь ты не быть, но кандидатом быть обязан!» - хохочет он [Там же, с. 261]; «Да не хочуя этого! - отчаянно кричит Димка. - К чёрту! Думаешь, я мечтаю пойти по твоим стопам, думаешь, твоя жизнь для меня идеал?» [Там же, с. 284].

Во второй части повести, после того как Димка пережил стресс от расставания с любимой девушкой, тональность глаголов речевой деятельности кардинально изменилась. Ключевым словом стал глагол щепmamb, который лишь один раз использовал автор для характеристики эмоционального состояния героя, при этом семантика глагола входит в противоречие с ситуацией его использования, вербализуя внутренний конфликт героя: "Я его убью», - ше п тал Димка, спокойно шагая по шоссе [Там же, с .379]. Димка всё ещё старается быть сильным, следовать жёстким правилам, которые он сам для себя создал: он не может быть неудачником, ему стыдно показывать свои истинные чувства. Но кричать сил больше нет, и Димка перестает кричать:

- Димка! - о р а л он, - Как ты там? Прием.

-Тип-топ», - с к а з а л я в микрофон.

- Я просто в восторге! - к р и ча л Алька. - У нас отличные парни. А у вас?

- Поговорим дома, - с к а за л я [Там же, с. 486].

Используя глаголы речевого воздействия, автор описывает определенные изменения во взаимоотношениях Димки с матросами на судне, с товарищами, с братом. Частотными являются глаголы спросить (спрашивать) (15 употреблений), переводящие регистр общения на другой уровень отношений. В первой части повести данные глаголы употребляются очень редко (2 употребления) лишь с целью поддержать общение: "Как диссертация? назначили оппонентов?»-с п раши в а е т Димка [Там же, с. 260]; «A что у вас таниуют?» - спросил Димка [Там же, с. 329]. Во второй части они используются сначала как способ скрыть, завуалировать переживания героя: Я вернулся к своим ребятам и небрежно бросил: «Подклеил одну кадришку». «Правда, ничего себе кадришка?»-спросил я [Там же, с. 415], затем как способ установления взаимодействия: «A плавать-то мы будем?» спросил я [Там же, с. 414]; «Что такое, ребята? - спросил я. - Соли, что ли мало?» [Там же, с. 426]; «Скажи, капитан, - спросил я однажды Игоря, - зачем ты нам тогда назвал свой колхоз?» [Там же, с. 431]; «Ну как тебе наш колхоз?»-спрашиваю я. А он все поет. - Tbl теперь в основном поешь?»-спрашиваюя [Там же, с. 438]; «Что случилось? - тихо с прашиваю я, и уменя сжимается сердие. С мамой что-то?» [Там же, с. 446]. С точки зрения психологии экстравертной личности данное поведение Димки свидетельствует о его «вытесненных чувствах в ситуации любви» [Юнг, с. 266].

Таким образом, глаголы речевой деятельности позволяют не только индивидуализировать героя повести в конкретной речевой ситуации, в его общении с разными персонажами, но и показать динамику изменения его поведения. Используя глаголы, вводящие и характеризующие речь персонажа, В. П. Аксенову удалось показать ярко и рельефно «человека говорящего», передать особенности его речевого состояния в тот или иной момент его жизни, показать его поведение и настроение, дать развернутую и образную характеристику героя повести.

\section{Список литературы}

Аксенов Василий Павлович. Звездный билет: сборник. Москва: Эксмо. 2014. 640 с.

Белянин В. П. Психологическое литературоведение. М.: Генезис, 2006. 320 с.

Выготский Л. С. Собрание сочинений: в 6-ти т. Т. 1. Вопросы теории и истории психологии. М.: Педагогика, $1982.488 \mathrm{c}$.

Зимняя И. А. Речевая деятельность и психология речи // Основы теории речевой деятельности / Отв. ред. А. А. Леонтьев. М.: Наука, 2016. С. 64-72.

Кацнельсон С. Д. Типология языка и речевое мышление. Л.: Наука, 1972. 213 с.

Кон И.С. Психология ранней юности. М.: Просвещение, 1989. 255 с.

Кулагина И. Ю., Колюикий В. Н. Возрастная психология: Полный жизненный цикл развития человека. Учебное пособие для студентов высших учебных заведений. М.: ТЦ «Сфера», 2001. 464c.

Ляпон М.В. «Картина мира: языковое видение интроверта» // Русский мир сегодня; сб. статей. Вып. 1. / отв. ред. Л. П. Крысин. М.: Азбуковник, 2000. C. 199-207.

Ожегов С. И., Шведова Н. Ю. Толковый словарь русского языка: 80000 слов и фразеологических выражений. 4-е изд., дополненное. М.: Азбуковник, 1999.944 c.

Толковый словарь русских глаголов: Идеографическое описание. Английские эквиваленты. Синонимы. Антонимы / под ред. Л. Г. Бабенко. М.: Аст-пресс, $1999.698 \mathrm{c}$.

Юнг К. Г. Психологические типы. Пер. с нем. URL: http://www.klex.ru/1bt ( дата обращения:15.04.2019) 


\section{References}

Aksenov, V. P. (2014). Zvezdnyi bilet: sbornik [A Ticket to the Stars: A Collection of Stories]. 640 p. Moscow, Jeksmo. (In Russian)

Belianin, V. P. (2006). Psihologicheskoe literaturovedenie [Psychological Literary Criticism]. 320 p. Moscow, Genezis. (In Russian)

Iung, K. G. (2014). Psikhologicheskie tipy [Psychological Types]. Per. s nem. URL: http://www.klex.ru/1bt (accessed: 15.04.2019). (In Russian)

Kacnel'son, S. D. (1972). Tipologiia iazyka $i$ rechevoe myshlenie [Typology of Language and Speech Thinking]. 213 p. Leningrad, Nauka. (In Russian)

Kon, I. S. (1989). Psihologiia rannei iunosti [ Psychology of Early Youth]. 255 p. Moscow, Prosveshhenie. (In Russian)

Kulagina, I. Ju., Koliuckii, V. N. (2001). Vozrastnaia psihologiia: Polnyi zhiznennyi tsikl razvitiia cheloveka. Uchebnoe posobie dlia studentov vysshih uchebnyh zavedenii [Age Psychology: A Full Life Cycle of the Human Development. A Textbook for Students of Higher Educational Institutions]. 464 p. Moscow, TTs "Sfera". (In Russian)

\author{
Бормусова Лилия Фирдинантовна, \\ аспирант, \\ Казанский федеральный университет, \\ 420008, Россия, Казань, \\ Кремлевская, 18. \\ bormusova87@mail.ru
}

Liapon, M. V. (2000). Kartina mira: iazykovoe videnie introverta [Picture of the World: A Linguistic Vision of the Introvert]. Russkii mir segodnia; sb. statei. Vyp. 1. Otv. red. L. P. Krysin. Pp. 199-207. Moscow, Azbukovnik. (In Russian)

Ozhegov, S. I., Shvedova, N. Ju. (1999). Tolkovyi slovar' russkogo iazyka: 80000 slov i frazeologicheskih vyrazhenii [Explanatory Dictionary of the Russian Language: 80000 Words and Phraseological Expressions]. 4-e izd., dopolnennoe. 944 p. Moscow, Azbukovnik. (In Russian)

Tolkovyi slovar' russkih glagolov: Ideograficheskoe opisanie (1999) [Explanatory Dictionary of Russian Verbs: Ideographic Description]. Angliiskie ekvivalenty. Sinonimy. Antonimy. Pod red. L. G. Babenko. 698 p. Moscow, Ast-press. (In Russian)

Vygotskii, L. S. (1982). Sobranie sochinenii: v 6-ti t. T. 1. Voprosy teorii i istorii psikhologii [Collected Works: In Six Volumes. V. 1. Theory and History of Psychology]. 488 p. Moscow, Pedagogika. (In Russian)

Zimniaia, I. A. (2016). Rechevaia deiatel'nost' $i$ psihologiia rechi [Speech Activity and Psychology of Speech]. Osnovy teorii rechevoi deiatel'nosti. Otv. red. A. A. Leont'ev. Pp. 64-72. Moscow, Nauka. (In Russian)

The article was submitted on 30.05.2019

Поступила в редакцию 30.05.2019

\section{Bormusova Liliya Firdinantovna,}

graduate student,

Kazan Federal University,

18 Kremlyovskaya Str.,

Kazan, 420008, Russian Federation.

bormusova87@mail.ru 